\title{
On Exchange-Rate Movements and Gold-Price Fluctuations: Evidence for Gold- Producing Countries from a Nonparametric Causality-in-Quantiles Test*
}

\author{
Mehmet Balcilar ${ }^{1,2,3}$, Rangan Gupta ${ }^{2 *} \&$ Christian Pierdzioch $^{4}$
}

\author{
${ }^{1}$ Department of Economics, Eastern Mediterranean University, Famagustavia Mersin 10 Northern \\ Cyprus, Turkey \\ ${ }^{2}$ Department of Economics, University of Pretoria, Pretoria 0002, South Africa \\ ${ }^{3}$ IPAG Business Schools, Paris, France \\ ${ }^{4}$ Department of Economics, Helmut Schmidt University, Holstenhofweg 85, P.O.B. 700822, 22008 Hamburg, \\ German
}

\author{
*Correspondence author: Rangan Gupta rangan.gupta@up.ac.za \\ Mehmet Balcilar mehmet@mbalcilar.net \\ Christian Pierdzioch c.pierdzioch@hsu-hh.de
}

\begin{abstract}
The links between exchange-rate movements and gold-price fluctuations have been extensively studied in earlier research using various econometric techniques. Our contribution to this research is that we apply a novel nonparametric causality-in-quantiles test to study the causal links between exchange-rate movements and gold-price fluctuations. We use daily data for the sample period 1994-2015 for major gold-producing countries to illustrate the novel test. We find that, for the majority of countries, gold-price fluctuations help to predict in sample the returns and the volatility of exchange rates. While exchange-rate movements predict in sample gold volatility, they do not predict gold returns.
\end{abstract}

JEL classification: C32; C53; F31; Q02

Keywords: Gold price; Exchange rates; Causality test; Gold-producing countries

\section{Introduction}

A long-standing research question in empirical finance is whether and, if so, how gold-price fluctuations are linked to exchange-rate movements (see, for example, Joy 2011, Ciner et al. 2013, and Reboredo 2013, Beckmann et al. 2015). In an early contribution to this research, Beckers

\footnotetext{
* We would like to thank two anonymous referees for many helpful comments. Any remaining errors are solely ours.
} 
and Soenen (1984) argue that such links should exist because low U.S. interest rates should make a dollar investment less attractive while, at the same time, a zero-yield gold investment becomes more attractive. Hence, one would expect a positive correlation between gold-price fluctuations and exchange-rate movements. Exchange-rate movements may even cause gold-price fluctuations. Such causal effects of exchange-rate movements onto gold-price fluctuations may help investors to use investments in gold as a hedge or even as a safe haven against exchangerate movements (on the hedging and safe-haven hypothesis, see Baur and Lucey 2010; see also Beckmann et al. 2015). At the same time, for major gold-producing countries, gold-price fluctuations may help to predict exchange-rate movements. In recent literature, significant research has been undertaken to study whether commodity prices help to forecast exchange-rate movements of commodity-exporting countries (Chen and Rogoff 2003; Chen et al., 2010; among others). In yet another recent strand of literature, researchers apply quantile-regression techniques to shed light on how gold-price fluctuations are linked, across the entire conditional distribution of gold-price fluctuations, to movements of other asset prices (for example, Baur 2013, Zagaglia and Marzo 2013).

We contribute to the literature on the links between gold-price fluctuations and exchange-rate movements by using a novel nonparametric causality-in-quantiles test recently proposed by Balcilar et al. (forthcoming) to reconsider the causal links between exchange-rate movements and gold-price fluctuations. Because the nonparametric causality-in-quantiles test can be used to shed light on both directions of causality (from exchange-rate movements onto gold-price fluctuations and the other way round) our results also contribute to the recent literature on commodity currencies. Finally, the novel nonparametric causality-in-quantiles test also extends the literature that uses quantile-regression techniques to study how gold-price fluctuations are linked to movements of other asset prices. The causality-in-quantiles test combines the recently developed frameworks of $k$-th order causality of Nishiyama et al., (2011) and quantile causality of Jeong et al., (2012) and hence, can be considered to be a more general version of the former. The causality-in-quantile approach has the following novel properties: 1) It is robust to misspecification errors as it detects the underlying dependence structure between the time series under consideration. This property could prove to be particularly important as it is well known that asset prices in general and commodity market returns in particular display nonlinear dynamics, especially when we look at high-frequency data (Balcilar et al., forthcoming). 2) The new test renders it possible to test not only for causality-in-mean but also to study causality that may exist in the tails of the joint distribution of the variables, which, in turn, is particularly important when the dependent variable has fat-tails - something we know to hold for returns 
(Jeong et al., 2012; Balcilar et al., forthcoming). 3) Upon using the novel test, we are able to investigate causality-in-variance and, hence, to study volatility spillovers. In other words, even when causality in the conditional-mean may not exist, such volatility spillovers can give rise to higher-order interdependencies that only become visible once one studies the causal interplay of the variances of the time-series being studied.

Upon estimating the nonparametric causality-in-quantiles test on daily data for major goldproducing countries (sample period 1994-2015), we find strong evidence that returns of gold help to predict exchange-rate returns and volatility for the majority of countries. Exchange-rate returns, in turn, have no predictive power for gold returns, but help to predict gold volatility, where the strength of the test results exhibits an inverse U-shaped pattern across the quantiles of the conditional distribution of gold volatility.

We structure this research note as follows. In Section 2, we describe the nonparametric causalityin-quantiles test. In Section 3, we describe our data and summarize our empirical results. In Section 4, we offer some concluding remarks.

\section{Testing for Causality-in-Quantiles}

We present a novel test, as proposed by Balcilar et al. (forthcoming), for the detection of nonlinear causality via a hybrid approach based on the frameworks of Nishiyama et al. (2011) and Jeong et al. (2012). As in Jeong et al. (2012), the variable $x_{t}$ does not cause $y_{t}$ in the $\theta$-quantile with respect to the lag-vector of $\left\{y_{t-1}, \ldots, y_{t-p}, x_{t-1}, \ldots, x_{t-p}\right\}$ if ${ }^{1}$

$$
Q_{\theta}\left(y_{t} \mid y_{t-1}, \ldots, y_{t-p}, x_{t-1}, \ldots, x_{t-p}\right)=Q_{\theta}\left(y_{t} \mid y_{t-1}, \ldots, y_{t-p}\right)
$$

$x_{t}$ causes $y_{t}$ in the $\theta$ th quantile with respect to $\left\{y_{t-1}, \ldots, y_{t-p}, x_{t-1}, \ldots, x_{t-p}\right\}$ if

$$
Q_{\theta}\left(y_{t} \mid y_{t-1}, \ldots, y_{t-p}, x_{t-1}, \ldots, x_{t-p}\right) \neq Q_{\theta}\left(y_{t} \mid y_{t-1}, \ldots, y_{t-p}\right)
$$

where $Q_{\theta}\left(y_{t} \mid \cdot\right)=\theta$ th quantile of $y_{t}$ depending on $t$ and $0<\theta<1$. In terms of notation, we let $Y_{t-1} \equiv\left(y_{t-1}, \ldots, y_{t-p}\right), X_{t-1} \equiv\left(x_{t-1}, \ldots, x_{t-p}\right)$, and $Z_{t}=\left(X_{t}, Y_{t}\right)$ and $F_{y_{t} \mid Z_{t-1}}\left(y_{t} \mid Z_{t-1}\right)$ denote the conditional distribution of $y_{t}$ given $Z_{t-1}$ and $Y_{t-1}$, where $F_{y_{t} \mid Y_{t-1}}\left(y_{t} \mid Y_{t-1}\right)$ is assumed to be absolutely continuous in $y_{t}$ for almost all $Z_{t-1}$. Upon defining $Q_{\theta}\left(Z_{t-1}\right) \equiv Q_{\theta}\left(y_{t} \mid Z_{t-1}\right)$ and $Q_{\theta}\left(Y_{t-1}\right) \equiv Q_{\theta}\left(y_{t} \mid Y_{t-1}\right)$, we have $F_{y_{t} \mid Z_{t-1}}\left\{Q_{\theta}\left(Z_{t-1}\right) \mid Z_{t-1}\right\}=\theta$ with probability one. Consequently, the hypotheses to be tested based on the definitions in Eqs. (1) and (2) are

$$
H_{0}=P\left\{F_{y_{t} \mid Z_{t-1}}\left\{Q_{\theta}\left(Y_{t-1}\right) \mid Z_{t-1}\right\}=\theta\right\}=1
$$

\footnotetext{
${ }^{1}$ The exposition in this section closely follows Nishiyama et al. (2011) and Jeong et al. (2012).
} 


$$
H_{1}=P\left\{F_{y_{t} \mid Z_{t-1}}\left\{Q_{\theta}\left(Y_{t-1}\right) \mid Z_{t-1}\right\}=\theta\right\}<1
$$

Jeong et al. (2012) use the distance measure $J=\left\{\varepsilon_{t} E\left(\varepsilon_{t} \mid Z_{t-1}\right) f_{Z}\left(Z_{t-1}\right)\right\}$, where $\varepsilon_{t}=$ regression error and $f_{Z}\left(Z_{t-1}\right)=$ marginal density function of $Z_{t-1}$. The regression error emerges based on the null in Eq. (3), which can only be true if and only if $E\left[\mathbf{1}\left\{y_{t} \leq Q_{\theta}\left(Y_{t-1}\right) \mid Z_{t-1}\right\}\right]=\theta$ or, equivalently, $\mathbf{1}\left\{y_{t} \leq Q_{\theta}\left(Y_{t-1}\right)\right\}=\theta+\varepsilon_{t}$, where $\mathbf{1}\{\cdot\}=$ indicator function. Jeong et al. (2012) specify the distance measure, $J \geq 0$, as follows:

$$
J=E\left[\left\{F_{y_{t} \mid Z_{t-1}}\left\{Q_{\theta}\left(Y_{t-1}\right) \mid Z_{t-1}\right\}-\theta\right\}^{2} f_{Z}\left(Z_{t-1}\right)\right]
$$

We have $J=0$ if and only if $H_{0}$ in Eq. (3) is true, while $J>0$ holds under $H_{1}$ in Eq. (4). Jeong et al. (2012) show that the feasible kernel-based test statistic for $J$ has the following form: ${ }^{2}$

$$
\hat{J}_{T}=\frac{1}{T(T-1) h^{2 p}} \sum_{t=p+1}^{T} \sum_{s=p+1, s \neq t}^{T} K\left(\frac{Z_{t-1-} Z_{s-1}}{h}\right) \hat{\varepsilon}_{t} \hat{\varepsilon}_{s}
$$

where $K(\cdot)=$ kernel function with bandwidth $h, T=$ sample size, $p=$ lag-order, and $\hat{\varepsilon}_{t}=$ estimate of the regression error, computed as

$$
\hat{\varepsilon}_{t}=\mathbf{1}\left\{y_{t} \leq \hat{Q}_{\theta}\left(Y_{t-1}\right)-\theta\right\}
$$

We use a nonparametric kernel method to estimate the $\theta$ th conditional quantile of $y_{t}$ given $Y_{t-1}$ as $\hat{Q}_{\theta}\left(Y_{t-1}\right)=\hat{F}_{y_{t} \mid Y_{t-1}}^{-1}\left(\theta \mid Y_{t-1}\right)$, where $\hat{F}_{y_{t} \mid Y_{t-1}}\left(y_{t} \mid Y_{t-1}\right)=$ Nadarya-Watson kernel estimator:

$$
\hat{F}_{y_{t} \mid Y_{t-1}}\left(y_{t} \mid Y_{t-1}\right)=\frac{\sum_{s=p+1, s \neq t}^{T} L\left(\frac{Y_{t-1}-Y_{s-1}}{h}\right) \mathbf{1}\left(y_{s} \leq y_{t}\right)}{\sum_{s=p+1, s \neq t}^{T} L\left(\frac{Y_{t-1}-Y_{s-1}}{h}\right)},
$$

with $L(\cdot)=$ the kernel function and $h$ the bandwidth.

In an extension of the Jeong et al. (2012) framework, we develop a test for the 2nd moment. To this end, we use the nonparametric Granger-quantile-causality approach by Nishiyama et al. (2011). In order to illustrate the causality in higher order moments, we assume

$$
y_{t}=g\left(Y_{t-1}\right)+\sigma\left(X_{t-1}\right) \varepsilon_{t},
$$

\footnotetext{
2 The differences, which arise from using the estimated indicator function in Eq. (7), between the ideal test statistic $J_{T}$ based on $Q_{\theta}\left(Y_{t-1}\right)$ and the feasible test statistic $\hat{J}_{T}$ given in Eq. (10) follow a second order degenerate $U$-statistic. By using the result that a second order degenerate $U$-statistic has an asymptotically normal distribution, Jeong et al. (2012) establish the asymptotically normality of the $\hat{J}_{T}$ statistic under a $\beta$-mixing process.
} 
where $\varepsilon_{t}=$ white noise process, and $g(\cdot)$ and $\sigma(\cdot)=$ unknown functions that satisfy certain conditions for stationarity. This specification not only allows for Granger-type causality testing from $x_{t}$ to $y_{t}$, but could possibly detect the "predictive power" from $x_{t}$ to $y_{t}^{2}$ when $\sigma(\cdot)$ is a general nonlinear function. Hence, the Granger causality-in-variance definition does not require an explicit specification of squares for $X_{t-1}$. We re-formulate Eq. (9) into a null and alternative hypothesis for causality in variance as follows:

$$
\begin{aligned}
& H_{0}=P\left\{F_{y_{t}^{2} \mid Z_{t-1}}\left\{Q_{\theta}\left(Y_{t-1}\right) \mid Z_{t-1}\right\}=\theta\right\}=1, \\
& H_{1}=P\left\{F_{y_{t}^{2} \mid Z_{t-1}}\left\{Q_{\theta}\left(Y_{t-1}\right) \mid Z_{t-1}\right\}=\theta\right\}<1 .
\end{aligned}
$$

To obtain a feasible test statistic for testing the null hypothesis in Eq. (10), we replace $y_{t}$ in Eq. (6) - (8) with $y_{t}^{2}$. Incorporating the Jeong et al. (2012) approach, we overcome the problem that causality in the conditional 1 st moment (mean) imply causality in the 2 nd moment (variance). Specifically, we interpret the causality in higher-order moments using the following model:

$$
y_{t}=g\left(X_{t-1}, Y_{t-1}\right)+\epsilon_{t}
$$

Thus, higher order quantile causality can be specified as:

$$
\begin{gathered}
H_{0}=P\left\{F_{y_{t}^{k} \mid Z_{t-1}}\left\{Q_{\theta}\left(Y_{t-1}\right) \mid Z_{t-1}\right\}=\theta\right\}=1 \quad \text { for } k=1,2, \ldots, K, \\
H_{1}=P\left\{F_{y_{t}^{k} \mid Z_{t-1}}\left\{Q_{\theta}\left(Y_{t-1}\right) \mid Z_{t-1}\right\}=\theta\right\}<1 \quad \text { for } k=1,2, \ldots, K .
\end{gathered}
$$

Integrating the entire framework, we define that $x_{t}$ Granger causes $y_{t}$ in quantile $\theta$ up to the $K$-th moment utilizing Eq. (10) to construct the test statistic of Eq. (6) for each $k$. However, it can be shown that it is not easy to combine the different statistics for each $k=1,2, \ldots, K$ into one statistic for the joint null in Eq. (13) because the statistics are mutually correlated (Nishiyama et al. 2011). To efficiently address this issue, we include a sequential-testing method as described by Nishiyama et al. (2011) with some modifications. Firstly, we test for nonparametric Granger causality in the 1 st moment $(k=1)$. Failure to reject the null for $k=1$, does not automatically lead to noncausality in the 2 nd moment and, thus, we construct the tests for $k=2$. Finally, we test for the existence of causality-in-variance, or the causality-in-mean and variance successively.

The empirical implementation of the causality-in-quantiles test requires specifying the bandwidth $h$, the lag order $p$, and the kernel type for $K(\cdot)$ and $L(\cdot)$ in Eq. (6) and (8). We determine the lag 
order using the Schwarz Information Criterion (SIC). ${ }^{3}$ The bandwidth is selected using the least squares cross-validation method. For $K(\cdot)$ and $L(\cdot)$, we use Gaussian kernels.

\section{Data and empirical results}

Our analysis is based on two daily variables: the returns of the gold price and returns of dollarbased exchange rates of the fourteen largest producers of gold (China, Australia, Russian Federation, Peru, South Africa, Canada, Mexico, Ghana, Colombia, Brazil, Indonesia, Argentina, Papua New Guinea, and Chile). ${ }^{4}$ Using returns ensures that the two variables are stationary - a requirement for our causality analysis. ${ }^{5}$ Gold returns are measured in terms of the firstdifferenced natural log of the gold fixing price at 3:00 P.M. (London time) in the London Bullion Market, based in U.S. Dollars, which is obtained from the FRED database of the Federal Reserve Bank of St. Louis. The dollar-based exchange rate returns are computed in the same fashion, with data on exchange rates obtained from Bloomberg. Given data availability, and for the sake of comparability across exchange rates, our sample covers the period of $29^{\text {th }}$ March, 1994 to $4^{\text {th }}$ December, 2015 for all countries.

Table 1 summarizes the results of tests of causality running from gold-price returns to exchangerate movements. The test results show that, for exchange-rate returns, noncausality can be rejected for the majority of countries, where South Africa and Ghana are exceptions. The test results also yield strong evidence for causality from gold-price returns onto exchange-rate volatility. Evidence of causality is strong across all quantiles of the conditional distribution of exchange-rate returns and exchange-rate volatility.

Table 2 summarizes the results of tests of causality running from exchange-rate returns to goldprice returns and volatility. While there is no evidence that exchange-rate returns cause gold returns, the test results provide strong evidence that exchange-rate returns cause gold volatility. Interestingly, the magnitude of the test statistic exhibits an inverted $\mathrm{u}$-shaped pattern across the quantiles of the conditional distribution of gold volatility. The only exception is Papua New Guinea, where the test results are insignificant. ${ }^{6}$

\footnotetext{
3 The SIC criterion is known to select a parsimonious number of lags and, thereby, prevents overparameterization problems associated with nonparametric approaches.

${ }_{4}^{4}$ We wanted to consider the top fifteen gold producers leaving out the United States (ranked third) for obvious reasons. However, Uzbekistan (ranked ninth) had to be dropped, as the Uzbekistani Som relative to the dollar is only available at annual frequency. Ranking of countries based on gold production in Kilograms can be found at http://www.indexmundi.com/minerals/?product=gold.

${ }^{5}$ Details of the unit root tests are available upon request from the authors.

${ }^{6}$ It is beyond the scope of our analysis to give a detailed economic explanation for why the results for Papua New Guinea are insignificant. One factor in this regard might be that an exchange-rate target zone around the official exchange rate oft he kina was introduced in June 2014 (see International Monetary Fund 2014).
} 
Table 1: Results of a nonparametric causality-in-quantiles test (gold-price fluctuations $\rightarrow$ exchange-rate movements)

\begin{tabular}{|c|c|c|c|c|c|c|c|c|c|c|c|c|c|c|}
\hline Quantiles & China & Russia & Australia & Peru & $\begin{array}{l}\text { South } \\
\text { Africa }\end{array}$ & Canada & Mexico & Indonesia & Ghana & Columbia & Brazil & Argentina & Chile & $\begin{array}{l}\text { Papua } \\
\text { New } \\
\text { Guinea }\end{array}$ \\
\hline \multicolumn{15}{|c|}{ Returns } \\
\hline 0.1 & 11.3088 & 10.3830 & 3.0206 & 7.8387 & 0.5199 & 5.3714 & 4.9660 & 13.4535 & 2.4768 & 5.9214 & 9.5979 & 12.8910 & 4.8189 & 9.0112 \\
\hline 0.2 & 24.5649 & 15.3101 & 3.2098 & 10.0058 & 0.7476 & 7.8357 & 6.1662 & 23.7404 & 1.9177 & 8.0117 & 21.7919 & 14.9107 & 6.7845 & 12.9948 \\
\hline 0.3 & 30.7106 & 16.9903 & 3.3588 & 8.2559 & 0.9772 & 8.1628 & 6.5816 & 19.7025 & 0.9571 & 8.3966 & 30.4858 & 229.3565 & 6.3010 & 10.0748 \\
\hline 0.4 & 23.1242 & 13.2283 & 3.5099 & 5.3019 & 0.5055 & 8.2490 & 4.0754 & 8.9109 & 0.3333 & 7.2962 & 29.2777 & 118.6362 & 2.9759 & 11.7492 \\
\hline 0.5 & 18.0816 & 3.5359 & 3.6600 & 7.2788 & 0.0974 & 8.0381 & 2.7129 & 1.1880 & 0.0684 & 6.6604 & 2.7689 & 42.7673 & 0.5891 & 9.9471 \\
\hline 0.6 & 14.6540 & 8.8279 & 3.8685 & 5.3995 & 0.0854 & 7.9339 & 3.4571 & 7.1080 & 0.1217 & 7.3183 & 17.5054 & 34.2838 & 1.4963 & 5.8545 \\
\hline 0.7 & 17.8917 & 16.5418 & 3.8834 & 8.0293 & 0.2427 & 8.4296 & 4.2749 & 15.7525 & 0.3699 & 8.3616 & 29.7631 & 29.3710 & 4.1242 & 6.9115 \\
\hline 0.8 & 21.9293 & 16.3418 & 3.2905 & 7.4396 & 0.3430 & 8.2447 & 4.8925 & 18.2726 & 0.7179 & 8.2219 & 23.1709 & 25.0000 & 5.5339 & 9.3192 \\
\hline 0.9 & 11.0610 & 9.0732 & 3.1330 & 4.9892 & 0.2975 & 5.4168 & 4.8399 & 14.8780 & 0.8725 & 5.8410 & 12.3291 & 14.2807 & 4.4989 & 6.2162 \\
\hline \multicolumn{15}{|c|}{ Volatility } \\
\hline 0.1 & 28.4033 & 14.5887 & 2.3655 & 12.1035 & 5.2900 & 1.5880 & 6.5615 & 15.6128 & 14.0480 & 8.3265 & 1.8449 & 46.1737 & 1.8445 & 31.7287 \\
\hline 0.2 & 9.6427 & 18.4774 & 3.5334 & 16.6564 & 6.9329 & 4.3924 & 9.4416 & 19.7974 & 15.1482 & 11.2224 & 7.9732 & 29.4593 & 4.3065 & 21.1028 \\
\hline 0.3 & 12.4164 & 21.0810 & 4.0154 & 18.9873 & 8.2117 & 4.9608 & 11.2866 & 23.0075 & 17.2881 & 12.5776 & 11.8897 & 27.0131 & 4.7847 & 21.6941 \\
\hline 0.4 & 16.0701 & 22.4937 & 4.5807 & 20.4456 & 10.2824 & 5.5805 & 12.0780 & 24.3350 & 18.7949 & 13.9656 & 12.6439 & 27.3517 & 6.6243 & 23.2600 \\
\hline 0.5 & 16.4331 & 23.4333 & 4.3760 & 20.7167 & 10.6370 & 6.4161 & 12.2561 & 24.5404 & 18.9681 & 14.6045 & 14.2727 & 26.7067 & 7.1213 & 23.8230 \\
\hline 0.6 & 16.5138 & 23.1779 & 4.2992 & 20.4895 & 9.1195 & 6.2972 & 12.1929 & 24.1561 & 18.2290 & 14.4922 & 11.9474 & 25.4320 & 7.9454 & 23.1652 \\
\hline 0.7 & 18.3938 & 21.6878 & 3.5357 & 18.7879 & 7.5973 & 4.7977 & 10.8997 & 22.4185 & 16.8936 & 12.8440 & 9.3922 & 22.9923 & 6.8975 & 21.4177 \\
\hline 0.8 & 12.2438 & 18.7583 & 3.7970 & 16.5997 & 5.6643 & 2.8490 & 9.2581 & 19.2991 & 14.9522 & 10.9919 & 4.0694 & 19.5587 & 4.8080 & 18.8816 \\
\hline 0.9 & 7.3722 & 13.7690 & 2.2575 & 11.7862 & 3.6641 & 2.6254 & 6.9917 & 14.4722 & 11.3000 & 7.8837 & 1.9780 & 14.4144 & 2.3696 & 14.0013 \\
\hline
\end{tabular}

Note: $95 \%$ critical value $=1.96$. Bold entries indicate the rejection of the null of noncausality. Countries sorted from left to right according to gold production as of 2012 . 
Table 2: Results of a nonparametric causality-in-quantiles test (exchange-rate movements $\rightarrow$ gold-price fluctuations)

\begin{tabular}{|c|c|c|c|c|c|c|c|c|c|c|c|c|c|c|}
\hline Quantiles & China & Russia & Australia & Peru & $\begin{array}{l}\text { South } \\
\text { Africa }\end{array}$ & Canada & Mexico & Indonesia & Ghana & Columbia & Brazil & Argentina & Chile & $\begin{array}{l}\text { Papua } \\
\text { New } \\
\text { Guinea }\end{array}$ \\
\hline \multicolumn{15}{|c|}{ Returns } \\
\hline 0.1 & 0.0014 & 0.0005 & 0.0006 & 0.0004 & 0.0005 & 0.0005 & 0.0005 & 0.0002 & 0.0000 & 0.0002 & 0.0002 & 0.0000 & 0.0005 & 0.0006 \\
\hline 0.2 & 0.0001 & 0.0000 & 0.0001 & 0.0003 & 0.0000 & 0.0000 & 0.0000 & 0.0001 & 0.0001 & 0.0008 & 0.0005 & 0.0008 & 0.0000 & 0.0000 \\
\hline 0.3 & 0.0001 & 0.0005 & 0.0001 & 0.0000 & 0.0005 & 0.0005 & 0.0005 & 0.0002 & 0.0001 & 0.0000 & 0.0002 & 0.0000 & 0.0005 & 0.0005 \\
\hline 0.4 & 0.0002 & 0.0000 & 0.0002 & 0.0003 & 0.0000 & 0.0000 & 0.0000 & 0.0004 & $\overline{0.0002}$ & 0.0000 & 0.0005 & 0.0000 & 0.0000 & 0.0006 \\
\hline 0.5 & 0.0000 & 0.0001 & 0.0003 & 0.0003 & 0.0001 & 0.0001 & 0.0001 & 0.0001 & 0.0000 & 0.0006 & 0.0000 & 0.0006 & 0.0001 & 0.0001 \\
\hline 0.6 & 0.0000 & 0.0001 & 0.0000 & 0.0003 & 0.0001 & 0.0001 & 0.0001 & 0.0002 & 0.0000 & 0.0002 & 0.0007 & 0.0002 & 0.0001 & 0.0007 \\
\hline 0.7 & 0.0007 & 0.0008 & 0.0006 & 0.0003 & 0.0008 & 0.0008 & 0.0008 & 0.0003 & 0.0001 & 0.0000 & 0.0004 & 0.0000 & 0.0008 & 0.0001 \\
\hline 0.8 & 0.0001 & 0.0002 & 0.0008 & 0.0003 & 0.0002 & 0.0002 & 0.0002 & 0.0006 & 0.0010 & 0.0006 & 0.0000 & 0.0001 & 0.0002 & 0.0000 \\
\hline 0.9 & 0.0006 & 0.0000 & 0.0003 & 0.0004 & 0.0000 & 0.0000 & 0.0000 & 0.0002 & 0.0017 & 0.0002 & 0.0002 & 0.0002 & 0.0000 & 0.0000 \\
\hline \multicolumn{15}{|c|}{ Volatility } \\
\hline 0.1 & 2.3433 & 2.6215 & 4.8241 & 4.0736 & 6.1500 & 5.0215 & 4.1248 & 3.5348 & 3.2632 & 5.5790 & 6.1079 & 2.7709 & 5.0666 & 0.0122 \\
\hline 0.2 & 6.4628 & 6.6644 & 8.6727 & 6.2914 & 8.2150 & 7.6318 & 6.2434 & 6.7768 & 4.7373 & 9.7289 & 12.0044 & 10.6589 & 9.2411 & 0.0175 \\
\hline 0.3 & 7.1246 & 5.8165 & 9.6124 & 7.5096 & 9.8486 & 8.8453 & 7.2562 & 8.4355 & 5.9189 & 10.8529 & 15.5493 & 14.2636 & 11.0536 & 0.0221 \\
\hline 0.4 & 7.9224 & 7.6731 & 9.5221 & 9.0160 & 10.3018 & 10.0298 & 8.3507 & 11.4983 & 6.6976 & 11.2754 & 19.3184 & 19.6101 & 12.1442 & 0.0275 \\
\hline 0.5 & 8.5083 & 9.0080 & 9.2889 & 9.6800 & 10.3600 & 10.5114 & 8.4479 & 11.5997 & 6.7387 & 12.0272 & 18.3275 & 22.4211 & 12.5055 & 0.0098 \\
\hline 0.6 & 8.7349 & 9.1734 & 9.6095 & 8.3319 & 10.6692 & 10.9291 & 8.1456 & 10.8089 & 6.5463 & 11.8594 & 19.6338 & 21.0601 & 12.0091 & 0.0138 \\
\hline 0.7 & 6.5907 & 7.8527 & 8.5946 & 7.6004 & 8.9099 & 9.4375 & 7.4787 & 8.7555 & 5.8301 & 10.5148 & 13.6718 & 18.4624 & 11.3136 & 0.0071 \\
\hline 0.8 & 5.9544 & 5.5626 & 7.4206 & 5.9304 & 7.2939 & 8.1335 & 5.9781 & 6.4751 & 4.8053 & 7.9051 & 10.0647 & 15.3805 & 9.0851 & 0.0046 \\
\hline 0.9 & 4.4890 & 3.8087 & 5.1033 & 4.3813 & 4.9704 & 5.2888 & 4.1188 & 4.0816 & 3.1732 & 4.7295 & 4.7572 & 6.4203 & 6.5303 & 0.0173 \\
\hline
\end{tabular}

Note: $95 \%$ critical value $=1.96$. Bold entries indicate the rejection of the null of noncausality. Countries sorted from left to right according to gold production as of 2012 . 


\section{Concluding remarks}

The research results we have laid out in this research note contribute to both the literature on the link between gold-price fluctuations and exchange-rate movements and the literature on commodity currencies. Using data for major gold-producing countries, we have shown that a novel nonparametric causality-in-quantiles test provides new insights into the in-sample causal links between gold-price fluctuations and exchange-rate movements in both their first and second moments. In future research, it is interesting to extend our analysis to a out-of-sample forecasting context, since in-sample predictability does not guarantee the same over the out-ofsample (Bonaccolto et al., 2015; on out-of-sample forecasting of gold-price fluctuations using variants of quantile-regression techniques, see also Pierdzioch et al. 2015, 2016).

\section{References}

Balcilar, M., Bekiros, S. and Gupta, R. (Forthcoming) The Role of News-Based Uncertainty Indices in Predicting Oil Markets: A Hybrid Nonparametric Quantile Causality Method. Empirical Economics.

Baur, D. G. and Lucey, B. M. (2010). Is Gold a Hedge or a Safe Haven? An Analysis of Stocks, Bonds and Gold. Financial Review, 45, 217-229.

Baur, D. G. (2013). The Structure and Degree of Dependence: A Quantile Regression Approach. Journal of Banking and Finance, 37, 786-798.

Beckers, S. and Soenen, L. (1984) Gold: More Attractive to Non-U.S. Than to U.S. Investors? Journal of Business Finance and Accounting, 11, 107-112.

Beckmann, J., Czudaj, R. and Pilbeam, K. (2015) Causality and Volatility Patterns Between Gold Prices and Exchange Rates. North American Journal of Economics and Finance, 34, 292-300.

Bonaccolto, G., Caporin, M., and Gupta, R. 2015. The Dynamic Impact of Uncertainty in Causing and Forecasting the Distribution of Oil Returns and Risk. Department of Economics, University of Pretoria, Working Paper No. 201564.

Chen, Y-C. and Rogoff, K. S. (2003). Commodity Currencies. Journal of International Economics, 60, 133-60.

Chen, Y-C., Rogoff, K.S. and Rossi, B. (2010). Can Exchange Rates Forecast Commodity Prices? Quarterly Journal of Economics, 125, 1145-94. 
Ciner, C., Gurdgiev, C. and Lucey, B.M. (2013) Hedges and Safe Havens: An Examination of Stocks, Bonds, Golkd, Oil, and Exchange Rates. International Review of Financial Analysis, 29, 202-211.

Fan, Y. and Li, Q. (1999). Central limit theorem for degenerate U-statistics of absolutely regular processes with applications to model specification tests. Journal of Nonparametric Statistics, 10, $245-271$.

International Monetary Fund (2014). Papua New Guinea - Staff Report for the 2014 Article IV consultation. Available at https://www.imf.org/external/pubs/ft/scr/2014/cr14325.pdf. Accessed July 14, 2016.

Jeong, K., Härdle, W. K. and Song, S.( 2012). A Consistent Nonparametric Test for Causality in Quantile. Econometric Theory, 28, 861-887.

Joy, M. (2011) Gold and the US dollar: Hedge or haven?, Finance Research Letters, 8, 120-131.

Nishiyama, Y., Hitomi, K., Kawasaki, Y. and Jeong, K. (2011) A Consistent Nonparametric Test for Nonlinear Causality - Specification in Time Series Regression. Journal of Econometrics, 165, $112-127$.

Pierdzioch, C, Risse, M, Rohloff, S (2015) A Real-Time Quantile-Regression Approach to Forecasting Gold Returns Under Asymmetric Loss. Resources Policy, 45, 299-306.

Pierdzioch, C., Risse, M. and Rohloff, S. (2016). A Quantile-Boosting Approach to Forecasting Gold Returns. North American Journal of Economics and Finance, 35, 38-55.

Reboredo, J. C. (2013) Is Gold a Safe Haven or a Hedge for the U.S. Dollar? Implications for Risk Management. Journal of Banking and Finance, 37, 2665-2676.

Zagaglia, P. and Marzo, M. (2013). Gold and the U.S. Dollar: Tales from the Turmoil. Quantitative Finance, 13, 571-582. 